\section{SAT0589 MUSCULOSKELETAL MANIFESTATIONS OCCUR PREDOMINANTLY IN PATIENTS WITH OLDER ONSET FAMILIAL MEDITERRANEAN FEVER}

Y. Endo ${ }^{1}$, T. Koga ${ }^{1}$, M. Umeda ${ }^{1}$, M. Ishida ${ }^{1}$, Y. Fujita ${ }^{1}$, S. Tsuji ${ }^{1}$, A. Takatani ${ }^{1}$, T. Shimizu ${ }^{1}$, R. Sumiyoshi ${ }^{1}$, T. Igawa ${ }^{1}$, S. Fukuil, A. Nishino ${ }^{1}$, S.-Y. Kawashiri, N. Imamoto ${ }^{1}$, K. Ichinose ${ }^{1}$, M. Tamai ${ }^{1}$, H. Nakamura ${ }^{1}$, T. Origuchi ${ }^{1}$, K. Agematsu ${ }^{2}$, A. Yachie ${ }^{3}$, J. Masumoto ${ }^{4}$, K. Mitiga ${ }^{5}$, A. Kawakami ${ }^{1} .{ }^{1}$ Department of Rheumatology, Unit of Translational Medicine, Graduate School of Biomedical Sciences, Nagasaki University, Nagasaki, ${ }^{2}$ Department of Infection and Host Defense, Graduate School of Medicine, Matsumoto; ${ }^{3}$ Department of Pediatrics, School of Medicine, Kanazawa University, Kanazawa; ${ }^{4}$ Proteo-Science Center, Ehime University, Matsuyama; ${ }^{5}$ Department of Rheumatology, Fukushima Medical University School of Medicine, Fukushima, Japan

Background: Our previous nation-wide survey showed the clinical manifestations and prevalence of Japanese Familial Mediterranean Fever (FMF) patients. However, the clinical differences between young-onset FMF (YOFMF), adultonset FMF (AOFMF), and late-onset FMF (LOFMF) have not been yet clarified. Objectives: We sought to compare between the clinical profile of patients with AOFMF, LOFMF and YOFMF and to determine the clinical characteristics of them.

Methods: We enrolled consecutively 395 patients in 2006-2017. Mutation detection in exons 1, 2, 3, and 10 of the MEFV gene was performed. We defined YOFMF, AOFMF and LOFMF as the onset of FMF $<20,20-39$ and $\geq 40$ years of age, respectively. We compared clinical manifestations and mutations in MEFV gene among these three groups.

Results: The median age at the onset of YOFMF, AOFMF and LOFMF were $12.5,28$ and 51 years old respectively. A family history of FMF and a mutation in exon 10 of the MEFV gene were significantly more frequent in groups with younger onset ([YOFMF 28\%, AOFMF 17\%, LOFMF 12\%; $p<0.01$ ], [YOFMF $51 \%$, AOFMF $33 \%$, LOFMF $19 \%$; $p<0.001$ ], respectively). In the accompanying manifestations during the attacks, abdominal pain and chest pain were significantly more frequent in groups with younger onset ([YOFMF 64\%, AOFMF 56\%, LOFMF 30\%; $p<0.001$ ], [YOFMF 45\%, AOFMF 33\%, LOFMF 24\%; $p<0.01$ ], respectively), whereas arthritis and muscle pain were significantly more frequent in groups with older onset ([YOFMF 32\%, AOFMF 48\%, LOFMF 62\%;p<0.001], [YOFMF 8\%, AOFMF 18\%, LOFMF 26\%;p<0.01], respectively). There was no significantly difference in the response to colchicine among the three groups.

\begin{tabular}{lccccccc}
\hline & $\begin{array}{c}\text { YOFMF } \\
(\mathrm{n}=182)\end{array}$ & $\begin{array}{c}\text { AOFMF } \\
(\mathrm{n}=115)\end{array}$ & $\begin{array}{c}\text { LOFMF } \\
(\mathrm{n}=90)\end{array}$ & $\begin{array}{c}\text { YOFMF } \\
\text { vo value } \\
\begin{array}{l}\text { vOFM } \\
\text { vs } \\
\text { LOFMF }\end{array}\end{array}$ & $\begin{array}{c}\text { YOFMF } \\
\text { Others }\end{array}$ & $\begin{array}{c}\text { Others } \\
\text { Lof } \\
\text { LOF }\end{array}$ \\
\hline Thoracic pain & $82 / 182(45 \%)$ & $38 / 115(33 \%)$ & $22 / 90(24 \%)$ & 0.0025 & 0.0015 & 0.0060 \\
Abdominal pain & $117 / 182(64 \%)$ & $64 / 115(56 \%)$ & $27 / 90(30 \%)$ & $<0.0001$ & 0.0001 & $<0.0001$ \\
Arthritis & $58 / 182(32 \%)$ & $55 / 115(48 \%)$ & $56 / 90(62 \%)$ & $<0.0001$ & $<0.0001$ & $<0.0001$ \\
Myalgia & $13 / 161(8 \%)$ & $16 / 91(18 \%)$ & $17 / 65(26 \%)$ & 0.0014 & 0.0012 & 0.0051 \\
$\begin{array}{l}\text { Erysipelas-like } \\
\text { erythema }\end{array}$ & $18 / 182(10 \%)$ & $16 / 115(14 \%)$ & $17 / 90(19 \%)$ & 0.11 & 0.10 & 0.08 \\
Headache & $25 / 161(16 \%)$ & $18 / 91(20 \%)$ & $10 / 65(15 \%)$ & 0.65 & 0.65 & 0.85 \\
\hline
\end{tabular}

Conclusions: Our results suggest that older onset FMF had a lower percentage of mutations in exon10 of the MEFV gene and predominantly presented arthritis and muscle pain during the attacks. It is thus important to distinguish them from other inflammatory diseases such as gout, adult Still's disease, and infectious arthritis.

Disclosure of Interest: None declared

DOI: 10.1136/annrheumdis-2018-eular.6307

\section{SAT0590 LONG-TERM EFFICACY AND SAFETY OF ADALIMUMAB BY AETIOLOGYIN PATIENTS WITH NON-INFECTIOUS UVEITIS IN THE VISUAL III TRIAL}

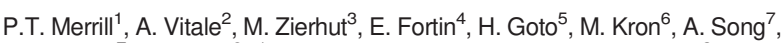
K. Douglas ${ }^{7}$, S. Pathai ${ }^{8} .{ }^{1}$ Rush University Medical Center, Chicago; ${ }^{2}$ University of Utah, Salt Lake City, USA; ${ }^{3}$ University of Tuebingen, Center of Ophthalmology, Tuebingen, Germany; ${ }^{4}$ University of Montreal, Montreal, Canada; ${ }^{5}$ Tokyo Medical University, Tokyo, Japan; ${ }^{6}$ AbbVie Deutschland GmbH and Co KG, Ludwigshafen, Germany; ${ }^{7}$ AbbVie Inc., North Chicago, USA; ${ }^{8}$ AbbVie Ltd, Maidenhead, UK

Objectives: To evaluate the long-term safety and efficacy of adalimumab in patients with non-infectious intermediate, posterior, or panuveitis, across different disease etiologies.
Methods: Adult patients in the Phase III VISUAL I/II trials, who met treatment failure (TF) criteria or who completed the study without TF, were eligible to enter the Phase III open-label extension study, VISUAL III, wherein patients received adalimumab 40 mg every other week. In this exploratory analysis, endpoints were analysed by six uveitis etiologies: i) idiopathic/other (IO), ii) birdshot chorioretinopathy (BCR), iii) multifocal choroiditis and panuveitis (MCP), iv) Vogt-Koyanagi-Harada syndrome (VKH), v) sarcoidosis, vi) Behçet's disease (BD). Endpoints assessed through Week 78 of treatment were proportion of patients with: no active inflammatory lesions in both eyes; anterior chamber (AC) cell grade $\leq 0.5+$ in both eyes; vitreous haze $(\mathrm{VH})$ grade $\leq 0.5+$ in both eyes; and quiescence (defined as no active inflammatory lesions AND AC cell grade $\leq 0.5+$ AND VH grade $\leq 0.5+$ ). Mean best corrected visual acuity (BCVA) was also assessed. Missing data were reported using non-responder imputation for categorical endpoints and last observation carried forward for continuous variables. Adverse events (AEs) were collected from first adalimumab dose in VISUAL III through the interim cut-off date of Oct 31, 2016

Results: Of 371 patients included in the intent-to-treat analysis, disease etiology subgroups were (n[\%]): IO (155 [41.8]); BCR (51 [13.7]); MCP (14 [3.8]); VKH (72 [19.4]); Sarcoidosis (52 [14.0]); BD (27 [7.3]). The proportion of patients achieving quiescence improved over time in all uveitis etiologic subgroups: IO 28.4\%/63.9\% (Week 0/Week 78), BCR 43.1\%/64.7\%, MCP 35.7\%/50.0\%, VKH 37.5\%/63.9\%, sarcoidosis $32.7 \% / 69.2 \%$, and BD $44.4 \% / 74.1 \%$. The proportions of patients with no active inflammatory lesions, $\mathrm{AC}$ cell grade $\leq 0.5+$, or $\mathrm{VH}$ grade $\leq 0.5+$, showed moderate increases or decreases between Weeks 0 and 78 within specific etiology subgroups; percentage ranges across all subgroups at Weeks $0 / 78$, were 60.8-87.5/57.1-78.8\% (no active inflammatory lesions), 47.2-92.2/50.0-77.8\% ( $A C$ cell grade $\leq 0.5+$ ), and 42.9-72.2/57.1-77.8\% (VH grade $\leq 0.5+$ ), respectively. Improvement or maintenance of mean BCVA was observed over time across the etiologic subgroups. AE rates were consistent with the VISUAL I and II trials.

Conclusions: Adalimumab increased the percentage of patients achieving quiescence and improved or maintained visual acuity at Week 78 of the VISUAL III study, with consistent results across uveitis etiologic subgroups. No new safety signals were detected with long-term adalimumab treatment.

Acknowledgements: AbbVie funded the study and provided medical writing support. All authors contributed to the development of the content. The authors and AbbVie reviewed and approved the abstract. The authors maintained control over the final content. Medical writing assistance was provided by Kevin Hudson PhD of 2theNth, which was funded by AbbVie Inc.

Disclosure of Interest: P. T. Merrill Consultant for: Steering Committee for the VISUAL studies and has served as a consultant and on advisory boards for Santen, Allergan, Alimera and pSivida, A. Vitale Consultant for: AbbVie and Aciont, M. Zierhut Consultant for: Scientific advisory board for AbbVie, Gilead, and Santen, E. Fortin Consultant for: advisory boards and as a consultant for AbbVie, Alcon and Allergan, H. Goto Consultant for: advisory boards for AbbVie, M. Kron Shareholder of: AbbVie, Employee of: AbbVie, A. Song Shareholder of: AbbVie, Employee of: AbbVie, K. Douglas Shareholder of: AbbVie, Employee of: AbbVie, S. Pathai Shareholder of: AbbVie, Employee of: AbbVie DOI: 10.1136/annrheumdis-2018-eular.2613

\section{SAT0591 DEMOGRAPHIC AND CLINICAL FEATURES OF} FAMILIAL MEDITERRANEAN FEVER PATIENTS

O. Ozdemir Isik ${ }^{1}$, B. Gonul ${ }^{2}$, A. Erol ${ }^{2}$, S. Tekeoglu ${ }^{1}$, D. Temiz Karadag ${ }^{1}$, A. Yazici ${ }^{1}$, A. Cefle ${ }^{1} .{ }^{1}$ Rheumatology; ${ }^{2}$ Internal Medicine, Kocaeli University School of Medicine, Kocaeli, Turkey

Background: Familial Mediterranean Fever (FMF) is an autosomal recessive genetic disorder that causes recurrent episodes of fever, poliserositis, arthritis, skin eruptions.

Objectives: In this study, we aim to present clinical and demographic features of FMF patients followed up in our clinic.

Methods: The clinical, demographic, genetic features and managements of 402 FMF patients (fulfilling Tel-Hashomer Diagnostic Criteria) were analysed.

Results: The mean age was $36.8 \pm 11.2$ years, mean diagnosis age was $28 \pm 11.9$ years, and mean disease duration was $189.2 \pm 124.5$ months, mean duration between onset of disease and onset of treatment was 93.6 \pm 104 months. Consanguineous marriage was detected in $7 \%{ }^{29}$ patients. Fever and abdominal pain both were initial symptoms in $72 \%$ of the patients, while $7 \%$ of them had chest pain, $4 \%$ had only fever, $15 \%$ had arthritis, $1 \%$ had erysipel-like erythema and $1.5 \%$ had inflammatory back pain as the first symptom of FMF (table 1).

Eight patients (2\%) were suffered from chronic kidney disease and 2 of them were on dialysis programme. Amyloidosis were identified in 14 patients (3.5\%) with biopsy.

At least one mutation of MEFV gene was detected in $78 \%$ patients There was no mutation in $8 \%$ patients. In $15 \%$ patients, MEFV gene analysis could not be done. The most frequent mutation was M694V mutation and its allel frequency was $54 \%$; the frequency of $\mathrm{V} 726 \mathrm{~A}, \mathrm{M} 680 \mathrm{I}, \mathrm{E} 148 \mathrm{Q}, \mathrm{R} 761 \mathrm{H}$ and $\mathrm{A} 744 \mathrm{~S}$ allels mutation 